\title{
Research on the design strategy of a fast packing box
}

\author{
Zhiliang Xia
}

Wenzhou Vocational \& Technical College, Wenzhou. 325035

Xia441@sina.com

Keywords: Packaging Box. Design. Plan.

\begin{abstract}
This design scheme is a fast packing box, including external cylinder, laminate, spring, inner tube and lock ring. The inner tube is installed inside the outer cylinder and The hook is installed in the groove of the guide slot. It has the characteristics of convenient disassembly and easy to use and high strength. It can quickly pack the bottles and bottles, avoid the breakage during transportation, and improve the packaging efficiency.
\end{abstract}

\section{Background}

Packaging is an indispensable link in the process of production and sale, which can protect and decorate the products. The existing bottles and cans are usually made of corrugated board, or plastic injection. Of two of them, corrugated board box is low in strength during use and easy to break in transit, causing the jar to crack and it takes a lot of time to bond. Although plastic packaging is of high strength, it is difficult to process the equipment at once. Moreover, And the processing cost is high, which can be used only once as the inner packing. And most of them are made of threaded connections, which have low efficiency and are not suitable for the use of outer packing when transporting.

\section{Technical Analysis}

The groove includes the top end and the bottom end . And the top end is parallel to the bottom end. The angle of the bottom end and the guide slot is $70-75^{\circ}$.As is shown in Figure 1.

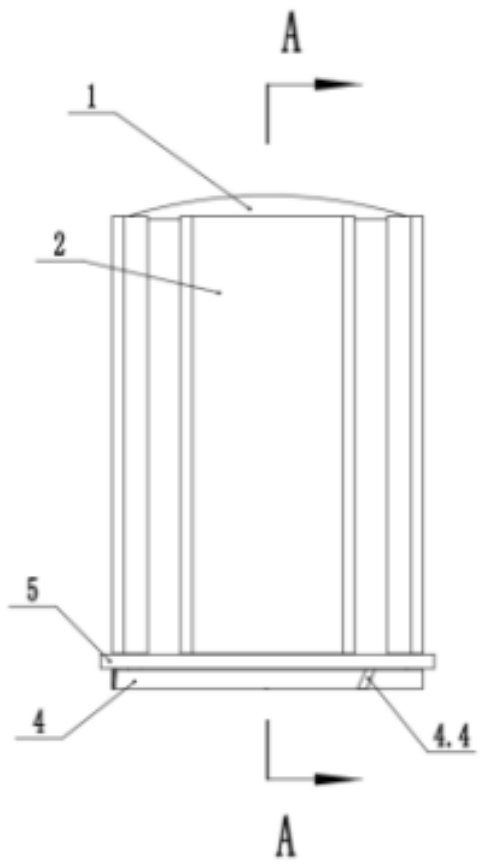

Figure 1 The Angle Of The Bottom End And The Guide Slot

The hook is "L", the horizontal edge of which is connected to the plate. And its The vertical 
edge and the plywood form the groove structure. When the inner tube is inside the outer barrel and is pushed upward, the spring is compressed and counterclockwise rotating the inner tube or outer cylinder, allowing the card hook to enter the slot through the groove structure. As is shown in Figure 2.

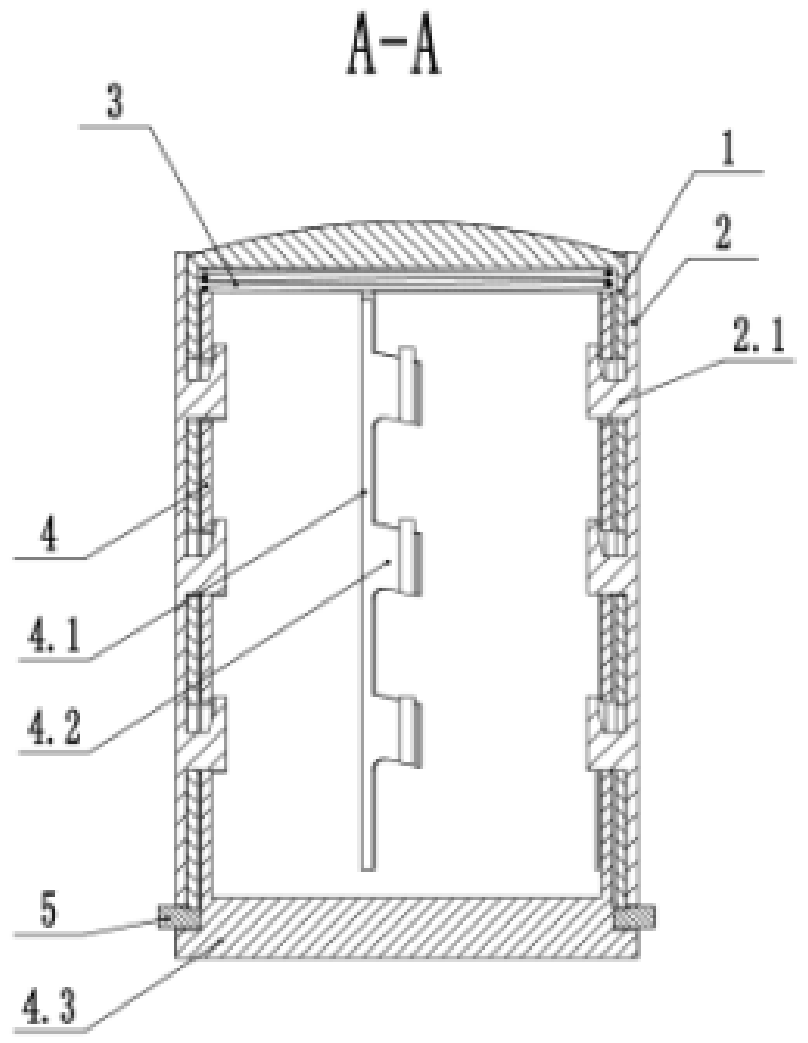

Figure 2 "L" Structure

The inner diameter of the locking ring is larger than the outer diameter of the locking plate, and the size of the groove radius is greater than that of the lock cylinder. The locking column is installed in the slot and slides up along the lock groove, allowing the lock ring to enter the clearance structure. Turn the locking ring counterclockwise or clockwise so that the lock slot and the lock column are staggered, and the lock ring is fixed in the gap structure. As is shown in Figure 3. 


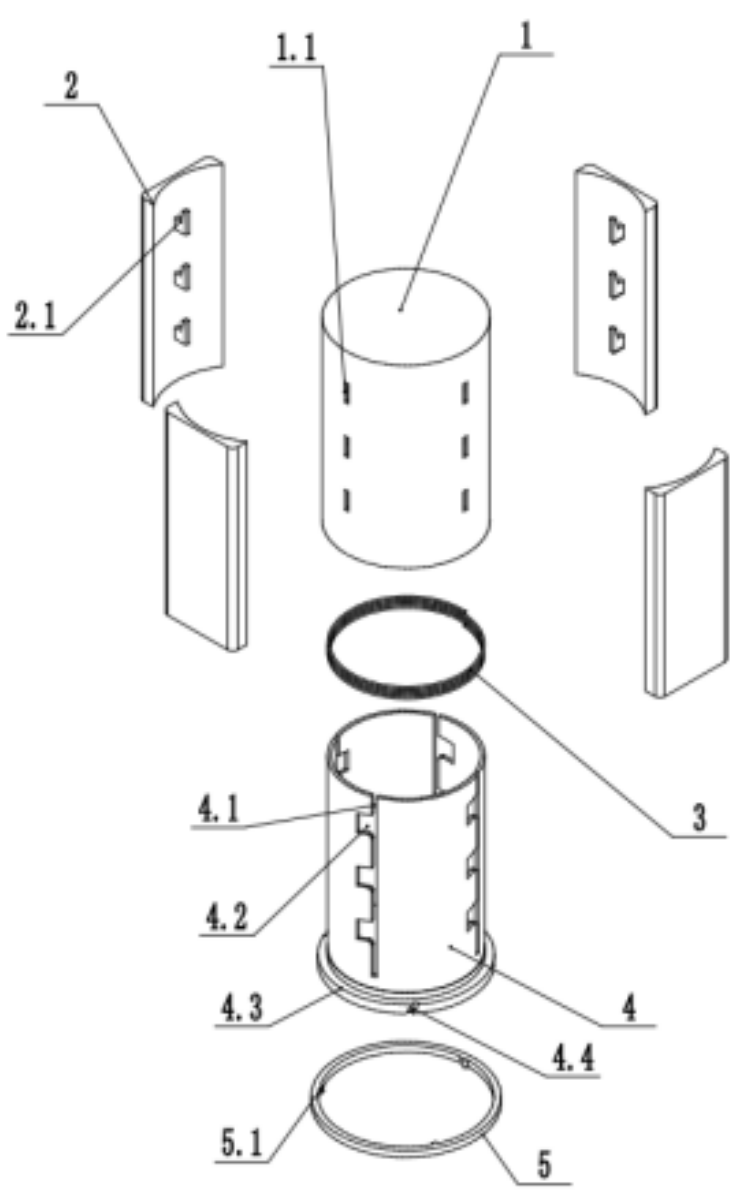

Figure 3 clamping ring

The outer tube and the patch board are one-piece structure. When the product contour size of the package is smaller, the outer tube and pasting plate are one-piece structure. : When the product contour size of the package is large, the outer cylinder and pasting plate are split structure. As is shown in Figure 4.

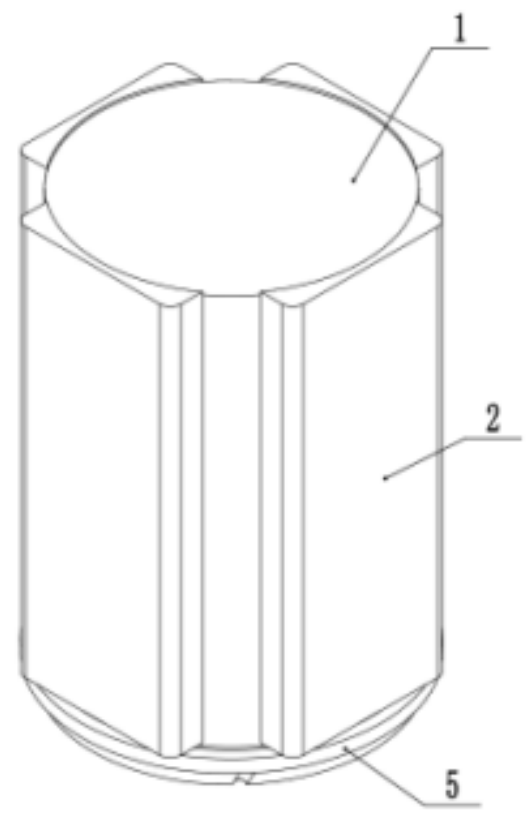

Figure 4 One Piece

The spring can be omitted according to the use requirement. When the product outline of the package is larger, the use of spring is omitted. The outer diameter of the spring is smaller than the inner diameter of the outer cylinder and is larger than the outer diameter of the inner cylinder. The 
inner diameter of the spring is smaller than the inner diameter of the inner cylinder. The beneficial effect is as follows: The invention has the characteristics of convenient disassembly and easy to use and high strength. It can quickly pack the bottles and bottles, avoid the fragmentation caused during transportation, and improve the packaging efficiency.

\section{Connection mode}

This paper provides a fast packing box, including outer tube 1, pasted plate 2, spring 3, inner tube 4 and ring 5 . The circumference of the outer cylinder is arranged with a positioning hole of 1.1 along its axial alignment. One end of the board 2 is a plane structure and the other is concave structure, the ends of which are arranged vertically with multiple card hooks 2.1 . In regard to Inner tube 4, the cylinder wall circumference is arranged with a vertical guide slot 4.1 and slot 4.2 which is located on the one side of the guide slot. And the slot 4.2 arranges the settings along the guide slot 4.1.

The bottom of inner tube 4 has a locking plate 4.3 and the locking plate has a locking slot 4.4. What's more, ring 5 has a locking column 5.1. The plate 2 concave structure end is installed in the outer cylinder 1 cylinder wall and the card hook 2.1 passes through the positioning hole 1.1. The top of the outer tube is a closed structure. The inner tube 4 is installed in the outer barrel 1 and the card hook 2.1 is installed in the slot 4.2 through the guide slot 4.1. Spring 3 is installed between the top of the inner tube 4 and the closed structure end of the top of the outer tube 1 . The locking plate 4.3 is set at the bottom of the outer barrel 1 and constitutes a gap structure. Locking ring 5 is installed in the clearance structure. Therefore, the rapid packaging of the larger bottle can be realized.

\section{Conclusion}

Based on the ideal embodiment of the present invention and the above description, relevant staff can make a variety of changes and modifications without deviating from the technical ideas of the invention. The technical scope of the invention is not limited to the contents of the instructions, and the technical scope must be determined according to the scope of claim.

\section{References}

[1] FISK A D. Designing for Older Adults: Principles and Creative Human Factors Approaches[M]. Boca Raton: CRC Press, 2004.

[2] MEYER J. Personal Vehicle Transportation Technolo $\square$ gy for Adaptive Aging[M]. Washington: the National Academies Press, 2004.

[3] SWIGART T F. Intems and the Older Driver[M]. New York: Mobility and Transportation Press, 2000.

[4] RICHARD S. The Decline of Public[M]. Shanghai: Shanghai Translation Publishing House, 2008.

[5] ZHAO Jiang-hong. The Meaning of Design Art[M]. Changsha: Hunan University Press, 2005.

[6] PETER THOMAS. Design Since 1945[M]. Chengdu: Sichuan People's Publishing House, 1998. 